\title{
Definitive Radiotherapy versus Surgery for the Treatment of Verrucous Carcinoma of the Larynx: A National Cancer Database Study
}

\author{
Anvesh R. Kompelli ${ }^{1}$ Michael H. Froehlich ${ }^{1}{ }^{10}$ Patrick F. Morgan ${ }^{10}$ Hong Li ${ }^{1}$ Anand K. Sharma ${ }^{1}$ \\ Cherie-Ann O. Nathan ${ }^{2}$ David M. Neskey ${ }^{1}$ \\ ${ }^{1}$ Department of Otolaryngology - Head and Neck Surgery, Medical \\ University of South Carolina, Charleston, SC, United States \\ ${ }^{2}$ Department of Otolaryngology - Head and Neck Surgery, Louisiana \\ State University Health Sciences Center Shreveport, Shreveport, LA, \\ United States \\ Address for correspondence Michael H. Froehlich, MD, Medical \\ University of South Carolina, 135 Rutledge Ave, Charleston, SC 29425- \\ 2503, United States (e-mail: michaelh.froehlich@gmail.com). \\ Int Arch Otorhinolaryngol 2022;26(3):e348-e356.
}

\begin{abstract}
Keywords

- verrucous carcinoma

- laryngeal neoplasms

- survival analysis

- surgical oncology

- radiotherapy
\end{abstract}

Introduction Traditionally, larger lesions of laryngeal verrucous carcinoma are treated with surgical excision, with definitive radiotherapy generally reserved for smaller lesions. However, data utilizing modern databases is limited.

Objective The authors sought to assess, utilizing the National Cancer Database, whether overall survival for patients with laryngeal verrucous carcinoma was equivalent when treated with definitive radiotherapy versus definitive surgery.

Methods A retrospective cohort study was conducted utilizing the National Cancer Database. All cases of laryngeal verrucous carcinoma within the National Cancer Database between 2006 and 2014 were reviewed. Patients with T1-T3 (American Joint Commission on Cancer 7th Edition) laryngeal verrucous carcinoma were included and stratified by treatment modality. Demographics, treatment, and survival data were analyzed.

Results A total of 392 patients were included. Two hundred and fifty patients underwent surgery and 142 received radiotherapy. The two groups differed in age, transition of care, clinical $T$ stage, and clinical stages. There was no significant difference in survival between T1-T3 lesions treated with surgery or radiotherapy $(p=0.32)$. Age, comorbidities, insurance status, and clinical T stage impacted overall hazard on multivariate analysis $(p<0.01)$. For patients treated with radiotherapy, age, insurance status, and clinical T stage were predictive of increased hazard.

Conclusion Overall survival is equivalent for patients with clinical T1 and clinical T2 laryngeal verrucous carcinoma treated with primary radiotherapy versus primary surgery. Thus, radiotherapy should be considered as a non-inferior treatment modality for certain patients with laryngeal verrucous carcinoma. received

May 18,2020

accepted

January 7, 2021

published online

November 3, 2021
DOI https://doi.org/ 10.1055/s-0041-1730304. ISSN 1809-9777.

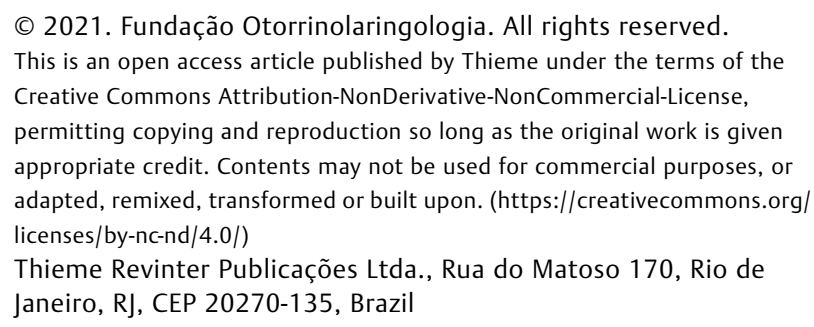

(c) 2021. Fundação Otorrinolaringologia. All rights reserved. This is an open access article published by Thieme under the terms of the Creative Commons Attribution-NonDerivative-NonCommercial-License, permitting copying and reproduction so long as the original work is given appropriate credit. Contents may not be used for commercial purposes, or adapted, remixed, transformed or built upon. (https://creativecommons.org/ licenses/by-nc-nd/4.0/) Thieme Revinter Publicações Ltda., Rua do Matoso 170, Rio de Janeiro, RJ, CEP 20270-135, Brazil 


\section{Introduction}

Verrucous carcinoma (VC) of the head and neck is a relatively uncommon head and neck pathology that most commonly arises within the oral cavity. Laryngeal verrucous carcinoma (LVC) accounts for approximately one third (35\%) of all VCs and represents only $\sim 1$ to $4 \%$ of all laryngeal cancers. ${ }^{1-3}$ This relatively low incidence makes it difficult to study disease recurrence and survival outcomes through single institutional studies and highlights the importance of analyzing disease characteristics using national cancer registries. Traditionally, most cases of LVC are surgically treated, as early studies have implied that LVC is less sensitive to conventional radiotherapy (RT) ${ }^{4-6}$ Furthermore, these tumors are well differentiated and, as such, hypothesized to be less radiosensitive. ${ }^{7}$ Additionally, previous works have raised concerns that LVC may undergo anaplastic transformation when exposed to radiation, with rates reported as high as $6.7 \%{ }^{6}$ However, recent evidence has demonstrated that this may not be the case. ${ }^{6,8}$ Furthermore, radiotherapy may be beneficial in a subset of patients. ${ }^{8,9}$

Since the publication of randomized trial the Radiation Therapy Oncology Group (RTOG) 91-11, there is now significant emphasis on laryngeal-preserving therapies, with the implementations of definitive RT for early stage disease (T1 and T2) or combined chemoradiotherapy (CRT) for more advanced T3 disease. ${ }^{10-12}$ For early stage glottic cancer, minimally invasive surgical techniques, including transoral laser microsurgery (TLM), are currently being utilized. ${ }^{13,14}$ However, surgicallybased organ-preserving therapy remains relatively limited, due in large part to the high rates of disease-specific survival observed with RT along with improved voice outcomes. ${ }^{15-17}$

Current evidence implies that verrucous histology alters the management of early-stage laryngeal cancers from primary RT to surgery. ${ }^{1,18}$ However, patients with LVC who are poor operative candidates or whose anatomy precludes minimally invasive surgery are left with few evidence-based treatment options for organ preservation. We hypothesized that with a large national database and modern radiation techniques, overall survival, when treated with RT, is equivalent to surgery for certain patients with LVC.

\section{Methods}

\section{Data Source}

The National Cancer Database (NCDB) is a hospital-based national cancer registry that is a joint program of the American College of Surgeons Commission on Cancer ( $\mathrm{CoC}$ ) and the American Cancer Society. The NCDB annually collects highquality and internally appraised cancer data from more than 1,500 CoC-accredited hospitals in the United States. It captures $\sim 70 \%$ of cancer diagnoses annually in the United States, and this makes it the world's largest clinical cancer registry. ${ }^{19}$

\section{Study Cohort}

Our institutional review board (IRB) policies were followed to obtain the data from the NCDB. Consent and authorization from the NCDB were obtained after an application was submitted through the NCDB Participant User File (PUF)
Application Manager. After review of the application, we were approved and granted access to de-identified data as a PUF. Furthermore, our institution does not require additional IRB approval in advance of using the PUF, given the previously established relationship with the NCDB as a CoCaccredited hospital which provides data.

Cases of verrucous carcinoma (VC) in the NCDB between 2006 and 2014 were identified using the International Classification of Disease for Oncology (3rd edition) histology code 8051. A total of 105,593 patients with head and neck cancer were available to be analyzed. Patients with laryngeal VC treated with either definitive surgery alone or definitive RT alone were included in this study. Patients treated with palliative intent, missing survival data, $\mathrm{T} 4$ disease, and cases of non-laryngeal VC were excluded. Cases of T4 were excluded as it is well established that primary RT is not effective for T4 verrucous laryngeal cancers. After excluding these patients, a total of 392 patients were included in the analysis (- Fig. 1).

\section{Clinical Variables}

The patient variables included age, sex, race, ethnicity, education, median household income, insurance status, and Charlson-Deyo comorbidity index (CDCI), to the extent made available by the NCDB. Disease covariates included AJCC clinical and pathologic stage as well as anatomic location within the larynx. The treatment characteristics assessed included treatment modality, facility type, and transition of care. Transition of care was defined as receiving diagnosis or treatment at more than one institution. Overall survival was the primary outcome, which was calculated as time from date of diagnosis to death or last date of follow-up.

\section{Statistical Methodology}

Descriptive statistics were used to summarize the variables. Discrete variables were summarized by the total number of patients in each category and its corresponding percentage. The chi-squared test and $t$-test were used to compare group differences. The Kaplan-Meier method was used to describe overall survival (OS). To assess the effect of covariates on the hazard of death, a univariate and multivariate Cox regression analysis was performed. First, we fit a univariate Cox regression model using the variables listed in Clinical Variables to determine whether any variables impacted overall survival. We assessed each variable one at a time. A $p$-value $\leq 0.2$ was used as the initial variable selection criteria, a standard $p$-value for univariate analysis. Then, a multivariate Cox regression model with forward variable selection and a $p$-value $\leq 0.05$ was used to identify the final covariates that, independently, had a significant impact on the overall hazard of death. The statistical analysis was performed in the SAS version 9.4 (SAS Inc., Cary, NC, USA) and the SPSS Statistics for Windows, Version 24.0 (IBM Corp., Armonk, NY, USA).

\section{Results}

\section{Patient Population}

A total of 392 patients were identified and included in the present study. A summary of the patient demographics is 


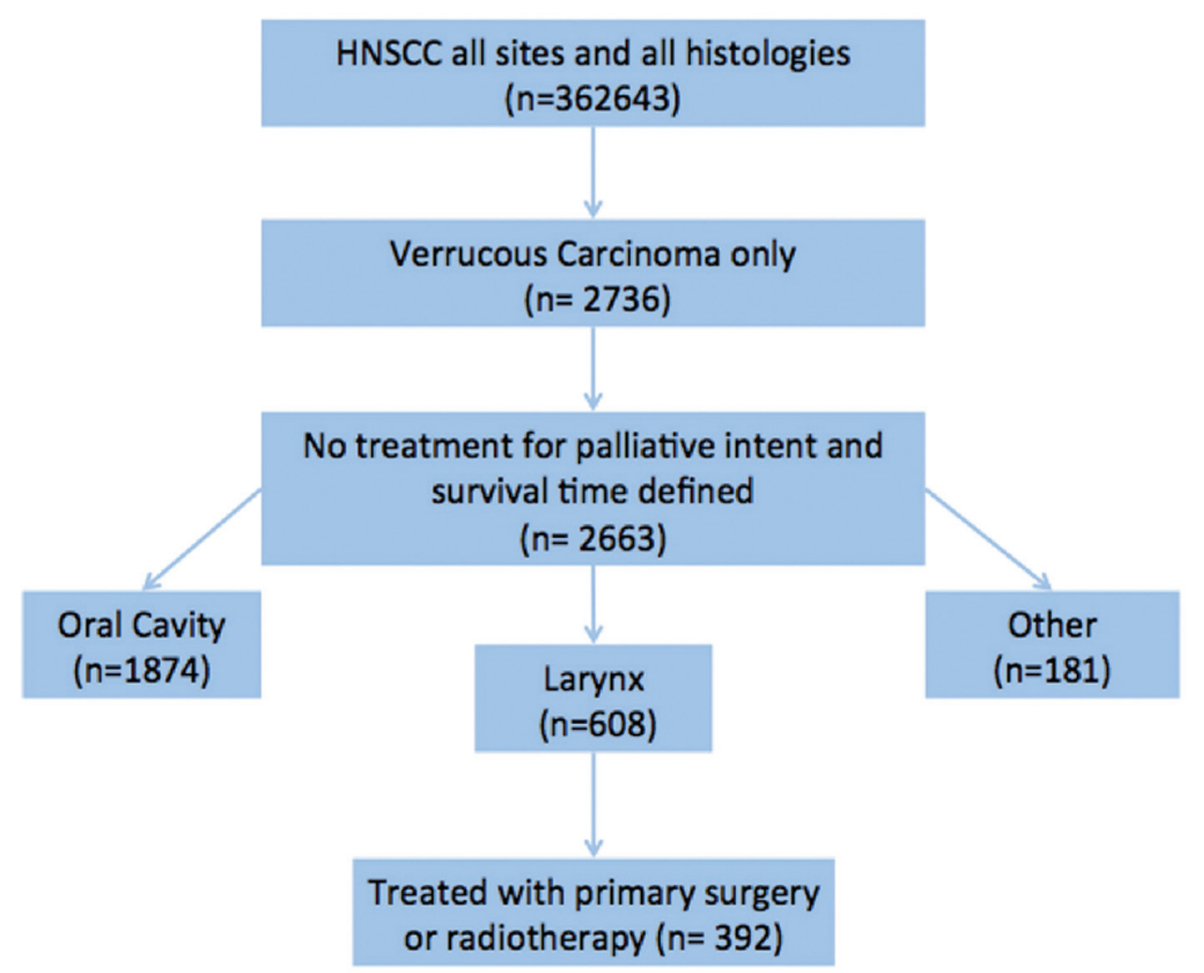

Fig. 1 Patient Selection. Illustration of how patients were selected for data analysis.

listed below (-Table 1). In this study, 250 (63.8\%) patients underwent surgery and 142 (36.2\%) underwent RT. Of note, there was a significant difference in age, transition of care, clinical T stage, and overall AJCC clinical stage in our cohort (-Table 1). Patients $>60$ years old were more likely to receive definitive RT when compared with their younger counterparts. A significantly higher number of T2 patients received $R T$.

\section{Impact of Primary Radiation versus Primary Surgery on Survival}

Utilizing the Kaplan-Meier method, survival for patients with clinical T1 to T3 LVC was similar, regardless of treatment modality (-Fig. 2). The median survival for patients with T1 to T3 LVC was 100 months (95\%CI: 93-108 months) for surgical patients and 84 months (95\%CI: 73-95months) for patients treated with RT. At the end of the study period, $73 \%$ of patients who underwent surgery and $61 \%$ of patients who received RT were alive. There was no significant difference in overall survival between surgery and RT ( Fig. 2A; $\boldsymbol{p}=0.32$ ). The 10-year overall survival for those who were treated surgically was $50.0 \%$ (95\% CI: 40.4-57.3\%), compared with $44.7 \%$ (95\% CI: 30.6-55.6\%) for those who received primary RT $(p=0.762)$. Furthermore, RT was equivalent to surgery for T1 (-Fig. 2B; $p=0.89$ ) and T2 lesions (-Fig. 2C; $p=0.15$ ). However, this finding did not hold for T3 lesions, as survival was significantly lower in these lesions treated with primary RT ( - Fig. 2D; $p=0.02$ ).

\section{Prognostic Factors of Overall Hazard in Laryngeal Verrucous Carcinoma}

On univariate analysis, age, $\mathrm{CDCI}$, insurance status, treatment modality, clinical T stage, clinical N stage, and clinical stage contributed to overall survival. However, after the multivariate Cox regression model, only age, $\mathrm{CDCI}$, insurance status, and clinical T stage significantly contributed to overall hazard. Of note, while RT significantly increased hazard by $63 \%$ $(p=0.02)$ on univariate analysis, this was no longer the case in the multivariate model (-Table 2). Patients between the ages of 60 and 70 had a 3.19-fold increase in hazard, and each decade increase was associated with nearly double the hazard (-Table 2 ). Having a comorbidity index $\geq 2$ was associated with a $59 \%$ increase in overall hazard. Patients with clinical T3 stage disease had a 2.15-fold increase in overall hazard (-Table 2 ).

\section{Factors that Impact Overall Hazard for Patients with LVC treated with Radiotherapy}

In an attempt to identify factors associated with increased hazard in patients treated with definitive radiotherapy, a univariate and multivariate Cox proportional hazard ratio on patients with clinically T1, T2, or T3 disease was performed. Age, insurance status, race, education status, clinical T stage, clinical $\mathrm{N}$ stage, and clinical stage were all associated with increased hazard on a univariate analysis (-Table 3 ). However, on multivariate analysis, age, insurance status, and clinical $\mathrm{T}$ stage were the only covariates associated with increased hazard ( - Table 3 ). Compared with patients younger than 50 , there was no significant difference for patients between 50 and 60 years of age. However, patients older than 70 had a 7.6-fold increase in overall hazard and patients older than 80 had 13.9-fold increase in overall hazard (-Table 3). Medicaid patients had an 8.1 -fold increase in overall hazard compared with Medicare. Increasing clinical T stage was associated with the largest contribution to overall 
Table 1 Demographics of patients treated with definitive surgery versus radiotherapy for patients with laryngeal verrucous carcinoma

\begin{tabular}{|c|c|c|c|}
\hline & $\begin{array}{l}\text { Primary } \\
\text { surgery } \\
250(63.8 \%)\end{array}$ & $\begin{array}{l}\text { Primary RT } \\
142(36.2 \%)\end{array}$ & $P$-value \\
\hline Age & & & 0.05 \\
\hline$<50$ & $64(25.6 \%)$ & $21(14.8 \%)$ & \\
\hline $50-60$ & $62(24.8 \%)$ & $36(25.4 \%)$ & \\
\hline $60-70$ & $66(26.4 \%)$ & 42 (29.6\%) & \\
\hline $70-80$ & 39 (15.6\%) & 37 (26.1\%) & \\
\hline$>80$ & $19(7.6 \%)$ & $\leq 10(4.1 \%)$ & \\
\hline Race & & & 0.27 \\
\hline White & $230(93.9 \%)$ & $129(92.1 \%)$ & \\
\hline Black & $14(5.7 \%)$ & $\leq 10(5.7 \%)$ & \\
\hline Other & $\leq 10(0.6 \%)$ & $\leq 10(2.1 \%)$ & \\
\hline Ethnicity & & & 0.10 \\
\hline Hispanic/Latino & $\leq 10(2.6 \%)$ & $\leq 10(6.0 \%)$ & \\
\hline $\begin{array}{l}\text { Not Hispanic/ } \\
\text { Latino }\end{array}$ & $228(97.4 \%)$ & $126(94.0 \%)$ & \\
\hline $\begin{array}{l}\text { Charlson-Deyo } \\
\text { comorbidity index* }\end{array}$ & & & 0.74 \\
\hline 0 & $121(69.0 \%)$ & 89 (69.7\%) & \\
\hline 1 & 39 (22.5\%) & 25 (20.5\%) & \\
\hline$\geq 2$ & $13(7.5 \%)$ & $12(9.8 \%)$ & \\
\hline Insurance* & & & 0.10 \\
\hline Medicare & $108(43.2 \%)$ & $47(33.1 \%)$ & \\
\hline Medicaid & $22(8.8 \%)$ & $14(9.9 \%)$ & \\
\hline Private/Other & $120(48 \%)$ & $81(57.0 \%)$ & \\
\hline Transition of care & 40 (16.4\%) & $40(28.1 \%)$ & 0.01 \\
\hline Education status & & & 0.69 \\
\hline$\geq 21.0 \%$ or more & $55(22.2 \%)$ & $30(21.6 \%)$ & \\
\hline $13.0-20.9 \%$ & 75 (29.8\%) & 43 (30.9\%) & \\
\hline $7.0-12.9 \%$ & 79 (31.9\%) & $38(27.3 \%)$ & \\
\hline$<7.0 \%$ & 40 (16.2\%) & $28(20.1 \%)$ & \\
\hline $\begin{array}{l}\text { Median household } \\
\text { income }\end{array}$ & & & 0.31 \\
\hline$<\$ 38,000$ & 48 (19.4\%) & $31(22.3 \%)$ & \\
\hline$\$ 38,000-\$ 47,999$ & 75 (30.4\%) & 39 (28.1\%) & \\
\hline$\$ 48,000-\$ 62,999$ & $72(29.2 \%)$ & 31 (22.3\%) & \\
\hline$\$ 63,000$ & $52(57.8 \%)$ & $38(42.2 \%)$ & \\
\hline Clinical T stage & & & $<0.01$ \\
\hline $\mathrm{T} 1$ & $122(69.3 \%)$ & 67 (55.8\%) & \\
\hline $\mathrm{T} 2$ & $28(15.9 \%)$ & $42(35.0 \%)$ & \\
\hline T3 & $20(11.4 \%)$ & $\leq 10(6.7 \%)$ & \\
\hline Clinical N stage & & & 0.20 \\
\hline No & 189 (98.4\%) & 117 (96.6\%) & \\
\hline
\end{tabular}

Table 1 (Continued)

\begin{tabular}{|l|l|l|l|}
\hline & $\begin{array}{l}\text { Primary } \\
\text { surgery } \\
250(63.8 \%)\end{array}$ & $\begin{array}{l}\text { Primary RT } \\
142(36.2 \%)\end{array}$ & $P$-value \\
\hline N1 & $\leq 10(1.6 \%)$ & $\leq 10(1.7 \%)$ & \\
\hline N2 & $0(0.0 \%)$ & $\leq 10(1.7 \%)$ & \\
\hline Clinical stage & & & $<0.01$ \\
\hline I & $122(69.3 \%)$ & $67(56.3 \%)$ & \\
\hline II & $28(15.9 \%)$ & $42(35.3 \%)$ & \\
\hline III & $20(11.4 \%)$ & $8(6.7 \%)$ & \\
\hline IV & $6(3.4 \%)$ & $2(1.7 \%)$ & \\
\hline
\end{tabular}

*Discrepancies in demographics are due to missing data within the NCDB.

hazard. Increasing from a T1 to a T2 stage lesion was associated with a 59.9-fold increase in overall hazard. Compared with T1 lesions, T3 lesions were associated with a 122.1-fold increase in overall hazard for patients treated with definitive RT ( - Table 3 ).

\section{Discussion}

Currently, evidence for nonsurgical management of LVC is sparse and controversial. ${ }^{5,6,8,20}$ In a systematic review of LVC, Ferlito et al. found that anaplastic transformation rate was as high as $6.7 \%$ with radiotherapy. ${ }^{6}$ However, since its publication in 1998, there has been limited evidence validating these findings. ${ }^{1,18}$ In the current study, we provide evidence demonstrating that patients with $\mathrm{T} 1$ or $\mathrm{T} 2$ lesions have an equivalent survival regardless of receiving surgery or RT. When considering the entire cohort, hazard was influenced by age, comorbidity index, insurance, and clinical T stage, but notably was not impacted by treatment modality. Furthermore, hazard for patients who receive RT was dictated by age, insurance, and clinical stage.

There is conflicting evidence regarding the risk of anaplastic transformation in patients with LVC treated with primary RT, with one study reporting anaplastic transformation in a small percentage of patients, while another reported no transformation. ${ }^{5,7}$ Despite this concern, 36.2\% of patients in our cohort were treated with definitive RT, suggesting that clinicians are weighing the theoretical risk of anaplastic transformation among other factors when deciding on treatment modality. The comfort of using RT in LVC may be due in part to the advances in radiotherapy that have developed over the last few decades, specifically the introduction of intensity-modulated radiation therapy (IMRT).

Organ-preserving surgery for patients with LVC can be a viable option; however, anatomic restrictions, functional impact of voice and swallowing, and perioperative risk factors highlight the need for increased investigation into the potential role for RT. To date, there are limited studies assessing the efficacy of definitive RT for patients with LVC. ${ }^{1,8}$ This is in contrast with conventional laryngeal squamous cell carcinoma (LSCC), in which organ preservation with RT for T1 
A.

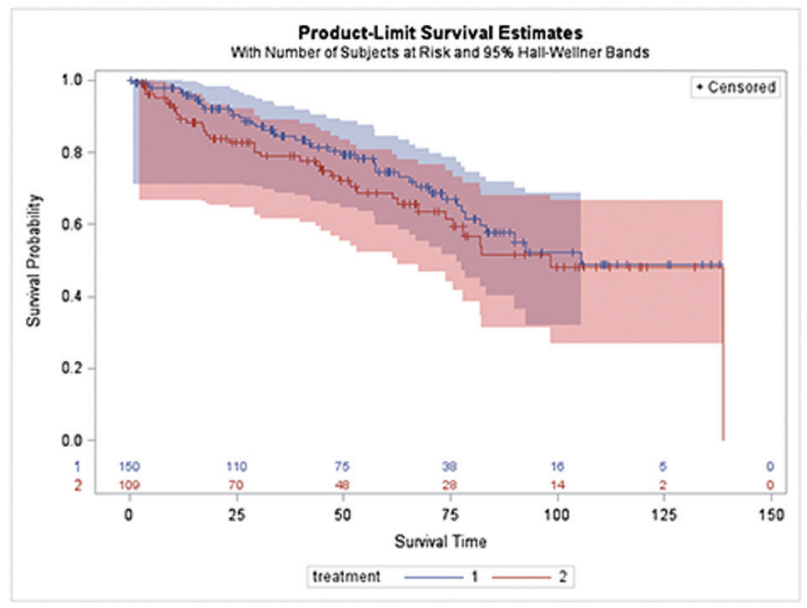

C.

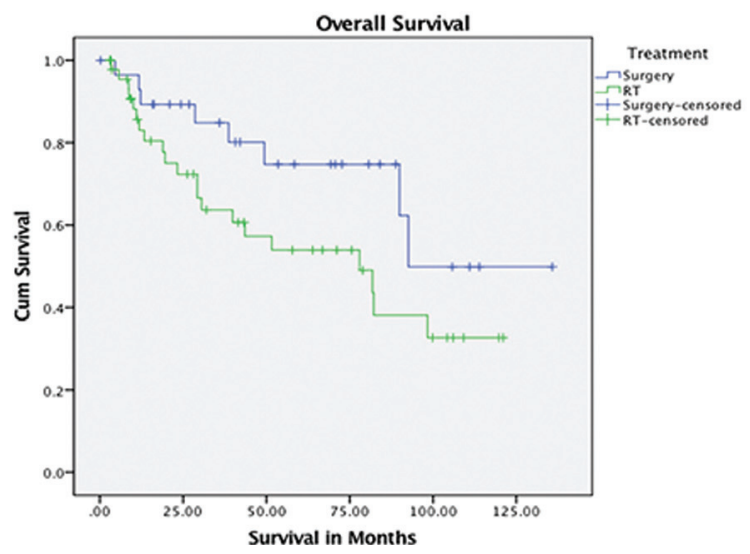

B.

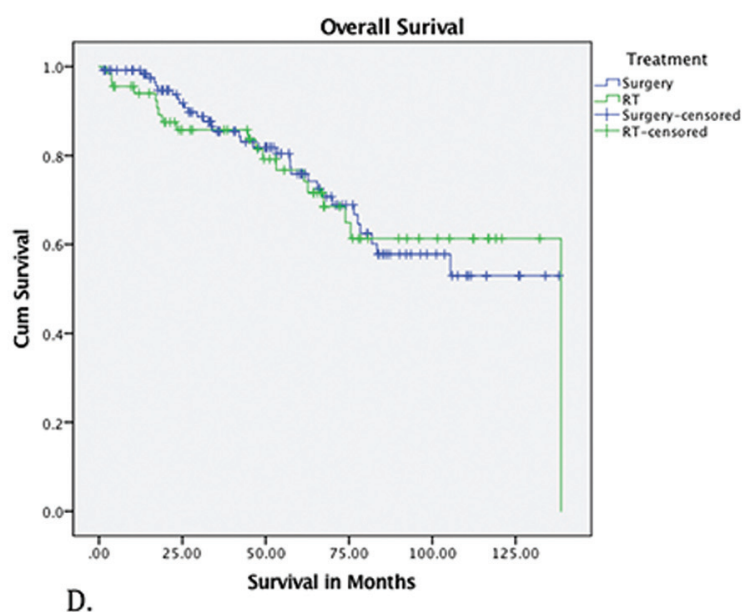

D.

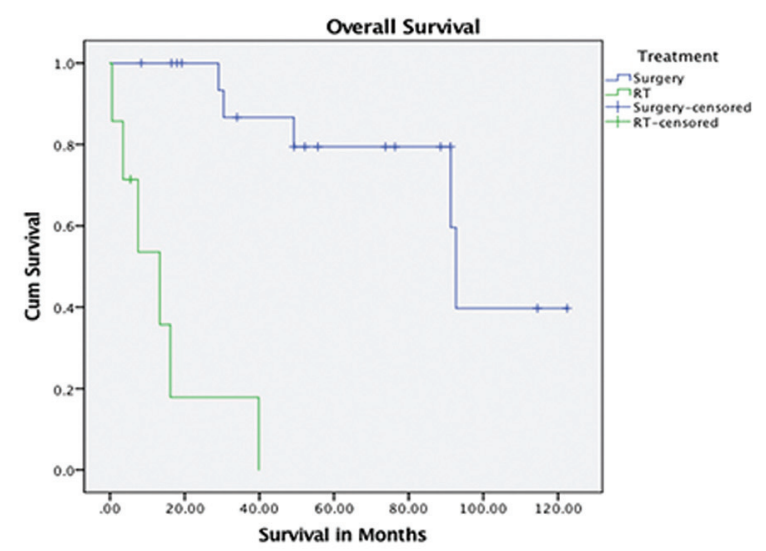

Fig. 2 (A) Overall Survival in All Patients treated with Definitive Radiotherapy versus Surgery. (B) Overall Survival in Clinical T1 Patients treated with Definitive Radiotherapy versus Surgery. (C) Overall Survival in Clinical T2 Patients treated with Definitive Radiotherapy versus Surgery. (D) Overall Survival in Clinical T3 Patients treated with Definitive Radiotherapy versus Surgery.

toT3 disease is well-established. ${ }^{13,21,22}$ The uncertainty of RT for LVC is due in part to Dubal et al., who demonstrated a worse 5-year survival in patients with LVC treated with primary RT compared with surgery with or without RT (90.2\% vs $80.6 \% p=0.02$ ), which contradicts the findings of our study. ${ }^{1}$ However, the authors did not stratify patients by T stage, which could potentially impact the authors' conclusions, particularly given that we observed differences in survival only in clinical T3 tumors. Based on current evidence, early LSCC treated with surgery or RT results in similar survival outcomes, but, for LVC, previous data suggest surgery may be a better treatment option. However, in the current study, we found patients with LVC who received definitive RT based on the NCCN guidelines for LSCC (i.e., T1T2) had similar survival outcomes to those of patients who underwent surgery. Our findings highlight organ preservation with RT appears to be an appropriate treatment option for patients with LVC.

Given that this patient population is of advanced age and subsequently at risk for increased co-morbidity, there was a risk that these factors could affect those selected to undergo RT by their treating physician. While age was associated with an increased likelihood of being selected for RT, there was no difference in the Charlson-Deyo morbidity index scores. Our analysis implicates that age, insurance status, and clinical stage significantly impact the survival outcomes of patients who receive RT. When considering a treatment modality for LVC, careful understanding of risk factors could help identify patients that could be treated with $\mathrm{RT}$ without a reduction in survival. Namely, patients younger than 80 years old who do not have locally advanced disease have a lower hazard associated with receiving RT. However, it is difficult to assess if patients over the age of 80 have increased hazard due to the disease or due to other confounding comorbidities. When weighing comorbidities and the risks associated with surgery, clinicians may consider RT for select patients who are poor operative candidates without sacrificing oncologic outcomes.

These findings are important, novel, and contradict several previously published works. ${ }^{1,5}$ Notwithstanding, there are limitations to the current study. As this is an NCDB study, we must acknowledge the limitations of utilizing this database. The NCDB allows investigators to study a large cohort of patients treated at $\mathrm{CoC}$ facilities, but key comorbidities, like 
Table 2 Univariate and multivariate Cox proportional hazard model to assess overall hazard for all patients with laryngeal verrucous carcinoma

\begin{tabular}{|c|c|c|c|c|}
\hline & $\begin{array}{l}\text { Univariate regression } \\
\mathrm{HR}(95 \% \mathrm{Cl})\end{array}$ & $P$-value & $\begin{array}{l}\text { Multivariate regression } \\
\text { HR }(95 \% \mathrm{Cl})\end{array}$ & $P$-value \\
\hline \multicolumn{5}{|l|}{ Age } \\
\hline$<50$ & 1 (ref) & & 1 (ref) & \\
\hline $50-60$ & $2.36(0.75-7.40)$ & 0.08 & $2.36(0.74-7.53)$ & 0.15 \\
\hline $60-70$ & $5.63(1.98-16.07)$ & $<0.01$ & $3.19(1.06-9.55)$ & 0.04 \\
\hline $70-80$ & $9.23(3.26-26.11)$ & $<0.01$ & $6.15(2.01-18.83)$ & $<0.01$ \\
\hline$>80$ & $20.30(6.70-61.52)$ & $<0.01$ & $13.38(3.96-45.25)$ & $<0.01$ \\
\hline \multicolumn{5}{|l|}{ Race } \\
\hline White & 1 (Ref) & & & \\
\hline Black & $20.01(0.82-4.37)$ & 0.08 & & \\
\hline Other & $1.29(0.17-9.30)$ & 0.80 & & \\
\hline \multicolumn{5}{|l|}{ Ethnicity } \\
\hline Not Hispanic/Latino & 1 (ref) & & & \\
\hline Hispanic/Latino & $2.04(0.82-5.08)$ & 0.12 & & \\
\hline \multicolumn{5}{|c|}{ Charlson-Deyo comorbidity index } \\
\hline 0 & 1 (ref) & & & \\
\hline 1 & $1.43(0.89-2.31)$ & 0.14 & 1 (ref) & \\
\hline$\geq 2$ & $2.94(1.49-5.83)$ & $<0.01$ & $1.59(1.11-2.27)$ & 0.01 \\
\hline \multicolumn{5}{|l|}{ Insurance } \\
\hline Medicare & 1 (ref) & & 1 (ref) & \\
\hline Medicaid & $2.56(0.97-6.73)$ & 0.06 & $2.33(0.81-6.66)$ & 0.11 \\
\hline Private/Other & $4.95(1.86-10.50)$ & $<0.01$ & $2.33(1.17-4.64)$ & 0.02 \\
\hline Transition of care & $0.83(0.50-1.37)$ & 0.46 & & \\
\hline \multicolumn{5}{|l|}{ Education status } \\
\hline$\geq 21.0 \%$ or more & 1 (ref) & & & \\
\hline $13.0-20.9 \%$ & $1.60(0.82-3.12)$ & 0.17 & & \\
\hline $7.0-12.9 \%$ & $1.43(0.73-2.83)$ & 0.29 & & \\
\hline$<7.0 \%$ & $1.37(0.67-2.83)$ & 0.38 & & \\
\hline \multicolumn{5}{|c|}{ Median household income } \\
\hline$<\$ 38,000$ & 1 (ref) & & & \\
\hline$\$ 38,000-\$ 47,999$ & $1.70(0.91-3.19)$ & 0.07 & & \\
\hline$\$ 48,000-\$ 62,999$ & $0.92(0.60-1.82)$ & 0.80 & & \\
\hline$\$ 63,000$ & $1.09(0.56-2.13)$ & 0.80 & & \\
\hline \multicolumn{5}{|l|}{ Treatment } \\
\hline Surgery & 1 (ref) & & & \\
\hline Radiotherapy & $1.63(1.08-2.48)$ & 0.02 & & \\
\hline \multicolumn{5}{|l|}{ Clinical T stage } \\
\hline $\mathrm{T} 1$ & 1 (ref) & & 1 (ref) & \\
\hline $\mathrm{T} 2$ & $1.64(1.03-2.59)$ & 0.04 & $1.45(0.90-2.34)$ & 0.12 \\
\hline $\mathrm{T} 3$ & $1.89(0.98-3.60)$ & 0.06 & $2.15(1.05-4.46)$ & 0.04 \\
\hline \multicolumn{5}{|l|}{ Clinical N stage } \\
\hline N0 & 1 (ref) & & & \\
\hline $\mathrm{N} 1$ & $5.10(1.22-21.26)$ & 0.03 & & \\
\hline
\end{tabular}


354 Definitive Radiotherapy versus Surgery for the Treatment of Verrucous Carcinoma Kompelli et al.

Table 2 (Continued)

\begin{tabular}{|c|c|c|c|c|}
\hline & $\begin{array}{l}\text { Univariate regression } \\
\text { HR }(95 \% \mathrm{Cl})\end{array}$ & $P$-value & $\begin{array}{l}\text { Multivariate regression } \\
\text { HR }(95 \% \mathrm{CI})\end{array}$ & $P$-value \\
\hline $\mathrm{N} 2$ & $1.63(0.23-11.75)$ & 0.63 & & \\
\hline \multicolumn{5}{|c|}{ Clinical stage } \\
\hline 1 & 1 (ref) & & & \\
\hline II & $1.53(0.95-2.46)$ & 0.06 & & \\
\hline III & $1.90(1.01-3.57)$ & 0.05 & & \\
\hline IV & $9.85(1.33-72.89)$ & 0.03 & & \\
\hline
\end{tabular}

${ }^{*} \mathrm{HR}$, hazard ratio

Table 3 Univariate and multivariate Cox proportional hazard model to assess risk for patients treated with definitive radiotherapy for laryngeal verrucous carcinoma

\begin{tabular}{|c|c|c|c|c|}
\hline & Unadjusted hazard ratio $(95 \% \mathrm{Cl})$ & $P$-value & Adjusted HR (95\% Cl) & $P$-value \\
\hline \multicolumn{5}{|l|}{ Age } \\
\hline$<50$ & 1 (ref) & & 1 (ref) & \\
\hline $50-60$ & $0.93(0.67-3.89)$ & 0.92 & $1.01(0.15-6.66)$ & 0.99 \\
\hline $60-70$ & $2.34(1.23-8.10)$ & 0.18 & $4.51(0.53-38.07)$ & 0.17 \\
\hline $70-80$ & $4.20(1.23-14.29)$ & 0.02 & $7.61(0.94-61.33)$ & 0.06 \\
\hline$>80$ & $10.31(2.28-6.63)$ & $<0.01$ & $13.91(1.34-144.56)$ & 0.03 \\
\hline \multicolumn{5}{|l|}{ Race } \\
\hline White & 1 (Ref) & & & \\
\hline Black & $6.59(2.27-19.01)$ & $<0.01$ & & \\
\hline Other & $1.57(0.21-11.52)$ & 0.66 & & \\
\hline \multicolumn{5}{|l|}{ Ethnicity } \\
\hline Not Hispanic/Latino & 1 (ref) & & & \\
\hline Hispanic/Latino & $2.21(0.77-6.31)$ & 0.14 & & \\
\hline \multicolumn{5}{|c|}{ Charlson-Deyo comorbidity index } \\
\hline 0 & 1 (ref) & & & \\
\hline 1 & $1.43(0.89-2.31)$ & 0.14 & & \\
\hline 2 & $2.94(1.49-5.83)$ & $<0.01$ & & \\
\hline \multicolumn{5}{|l|}{ Insurance } \\
\hline Medicare & 1 (ref) & & 1 (ref) & \\
\hline Medicaid & $3.75(1.05-13.35)$ & 0.04 & $8.14(1.27-52.17)$ & 0.03 \\
\hline Private/Other & $4.41(1.86-10.50)$ & $<0.01$ & $2.26(0.75-6.84)$ & 0.15 \\
\hline Transition of care & $0.59(0.29-1.15)$ & 0.12 & & \\
\hline \multicolumn{5}{|l|}{ Education status } \\
\hline$\geq 21 \%$ or more & 1 (ref) & & & \\
\hline $13-20.9 \%$ & $3.13(1.04-9.44)$ & 0.04 & & \\
\hline $7-12.9 \%$ & $2.68(0.88-8.16)$ & 0.08 & & \\
\hline$<7 \%$ & $2.51(0.80-8.16)$ & 0.11 & & \\
\hline \multicolumn{5}{|c|}{ Median household income } \\
\hline$<\$ 38,000$ & 1 (ref) & & & \\
\hline$\$ 38,000-\$ 47,999$ & $2.79(0.93-8.43)$ & 0.07 & & \\
\hline$\$ 48,000-\$ 62,999$ & $1.88(0.60-5.94)$ & 0.28 & & \\
\hline
\end{tabular}


Table 3 (Continued)

\begin{tabular}{|l|l|l|l|l|}
\hline & Unadjusted hazard ratio (95\% Cl) & $P$-value & Adjusted HR (95\% Cl) & $P$-value \\
\hline$\$ 63,000$ & $2.01(0.66-6.12)$ & 0.21 & & \\
\hline Clinical T stage & & & & \\
\hline T1 & 1 (ref) & & 1 (ref) & \\
\hline T2 & $2.07(1.10-3.90)$ & 0.02 & $59.94(3.46-1036-95)$ & 0.01 \\
\hline T3 & $14.0(5.22-37.38)$ & $<0.01$ & $122.14(1.69-8850.61)$ & 0.03 \\
\hline Clinical N stage & & & & \\
\hline N0 & 1 (ref) & & & \\
\hline N1 & $5.21(1.21-22.27)$ & 0.03 & & \\
\hline N2 & $1.22(0.17-8.89)$ & 0.85 & & \\
\hline Clinical stage & & & & \\
\hline I & $1($ ref) & & & \\
\hline II & $1.88(0.98-3.62)$ & 0.06 & & \\
\hline III & $12.32(4.82-31.48)$ & $<0.01$ & & \\
\hline IV & $7.92(1.02-61.46)$ & 0.05 & & \\
\hline
\end{tabular}

smoking status and ethanol use, are not recorded, which can impact patient outcomes. Furthermore, key data points in studying laryngeal cancer including time to laryngectomy, locoregional control, voice quality following therapy, and, perhaps most importantly, disease-specific survival, are not recorded. As mortality from LVC is relatively lower compared with other forms of laryngeal and head and neck cancers, disease-specific survival is a relevant outcome. ${ }^{23}$ However, due to the data made available through the NCDB, this outcome cannot be evaluated from this sample. In an attempt to account for locoregional control and avoid patients with salvage laryngectomy, only patients who received a single modality of therapy were included. Additionally, data collection within NCDB is incomplete, and, thus, staging and survival for all patients was not able to be included. The authors do not feel that these limitations take away from the significance of our findings.

Our findings also shed light on topics for future research, subgroup analysis of predictive variables and overall survival for laryngeal subsite (supra-glottis, glottis, and sub-glottis) and surgical modality (open resection versus endoscopic laser versus cold steel surgery) should be considered. Subsite location of LSCC may respond better to different treatment modalities (surgery versus RT) and also independently impact on overall survival. While LVC is known to have a predilection for the glottis, determining whether the differences found with regard to LSCC also exist with LVC is of particular interest. ${ }^{24}$ Furthermore, as previously stated, studies that can utilize data with disease-specific survival would be of value.

\section{Conclusion}

Despite its limitations, the present study highlights an important finding: survival is equivalent for patients with clinical T1 and clinical T2 LVC treated when treated with primary RT versus primary surgery. Thus, RT should be increasingly considered as a valid, non-inferior treatment modality for certain patients with LVC, particularly those who are poor surgical candidates. Future prospective studies evaluating survival outcomes based on laryngeal subsite, different surgical techniques, as well as comparing RT to other organ-preserving therapies, should be encouraged. Studies are also needed to investigate disease-specific survival and the true rate of anaplastic transformation using modern radiation techniques.

\section{Conflict of Interests}

The authors have no conflict of interests to declare.

\section{References}

1 Dubal PM, Svider PF, Kam D, Dutta R, Baredes S, Eloy JA. Laryngeal Verrucous Carcinoma: A Population-Based Analysis. Otolaryngol Head Neck Surg 2015;153(05):799-805

2 Koch BB, Trask DK, Hoffman HT, et al; Commission on Cancer, American College of Surgeons American Cancer Society. National survey of head and neck verrucous carcinoma: patterns of presentation, care, and outcome. Cancer 2001;92(01):110-120

3 López F, Williams MD, Cardesa A, et al. How phenotype guides management of non-conventional squamous cell carcinomas of the larynx? Eur Arch Otorhinolaryngol 2017;274(07):2709-2726

4 Ryan RE Jr, DeSanto LW, Devine KD, Weiland LH. Verrucous carcinoma of the larynx. Laryngoscope 1977;87(12):1989-1994

5 Ferlito A, Recher G. Ackerman's tumor (verrucous carcinoma) of the larynx: a clinicopathologic study of 77 cases. Cancer 1980;46 (07):1617-1630

6 Ferlito A, Rinaldo A, Mannarà GM. Is primary radiotherapy an appropriate option for the treatment of verrucous carcinoma of the head and neck? J Laryngol Otol 1998;112(02):132-139

7 Orvidas LJ, Olsen KD, Lewis JE, Suman VJ. Verrucous carcinoma of the larynx: a review of 53 patients. Head Neck 1998;20(03): 197-203 
8 Huang SH, Lockwood G, Irish J, et al. Truths and myths about radiotherapy for verrucous carcinoma of larynx. Int J Radiat Oncol Biol Phys 2009;73(04):1110-1115

9 Strojan P, Smid L, Cizmarevic B, Zagar T, Auersperg M. Verrucous carcinoma of the larynx: determining the best treatment option. Eur J Surg Oncol 2006;32(09):984-988

10 Wolf GT, Fisher SG, Hong WK, et al; Department of Veterans Affairs Laryngeal Cancer Study Group. Induction chemotherapy plus radiation compared with surgery plus radiation in patients with advanced laryngeal cancer. N Engl J Med 1991;324(24): 1685-1690

11 Adelstein D, Gillison ML, Pfister DG, et al. NCCN Guidelines Insights: Head and Neck Cancers, Version 2.2017. J Natl Compr Canc Netw 2017;15(06):761-770

12 Forastiere AA, Goepfert H, Maor M, et al. Concurrent chemotherapy and radiotherapy for organ preservation in advanced laryngeal cancer. N Engl J Med 2003;349(22):2091-2098

13 Mendelsohn AH, Remacle M. Transoral robotic surgery for laryngeal cancer. Curr Opin Otolaryngol Head Neck Surg 2015;23(02): 148-152

14 Agrawal N, Ha PK. Management of early-stage laryngeal cancer. Otolaryngol Clin North Am 2008;41(04):757-769, vi-vii

15 Rubinstein M, Armstrong WB. Transoral laser microsurgery for laryngeal cancer: a primer and review of laser dosimetry. Lasers Med Sci 2011;26(01):113-124

16 Chen AY, Fedewa S, Zhu J. Temporal trends in the treatment of early- and advanced-stage laryngeal cancer in the United States,
1985-2007. Arch Otolaryngol Head Neck Surg 2011;137(10): 1017-1024

17 Mendenhall WM, Amdur RJ, Morris CG, Hinerman RW. T1-T2NO squamous cell carcinoma of the glottic larynx treated with radiation therapy. J Clin Oncol 2001;19(20):4029-4036

18 Sciubba JJ, Helman JI. Current management strategies for verrucous hyperkeratosis and verrucous carcinoma. Oral Maxillofac Surg Clin North Am 2013;25(01):77-82, vi

19 Bilimoria KY, Stewart AK, Winchester DP, Ko CY. The National Cancer Data Base: a powerful initiative to improve cancer care in the United States. Ann Surg Oncol 2008;15(03):683-690

20 Edström S, Johansson SL, Lindström J, Sandin I. Verrucous squamous cell carcinoma of the larynx: evidence for increased metastatic potential after irradiation. Otolaryngol Head Neck Surg 1987;97(04):381-384

21 Taylor SM, Kerr P, Fung K, et al. Treatment of T1b glottic SCC: laser vs. radiation-a Canadian multicenter study. J Otolaryngol Head Neck Surg 2013;42(01):22

22 Kono T, Saito K, Yabe H, Uno K, Ogawa K. Comparative multidimensional assessment of laryngeal function and quality of life after radiotherapy and laser surgery for early glottic cancer. Head Neck 2016;38(07):1085-1090

23 Hoffman HT, Porter K, Karnell LH, et al. Laryngeal cancer in the United States: changes in demographics, patterns of care, and survival. Laryngoscope 2006;116(9 Pt 2, Suppl 111)1-13

24 Echanique KA, Desai SV, Marchiano E, et al. Laryngeal Verrucous Carcinoma. Otolaryngol Head Neck Surg 2017;156(01):38-45 